\title{
What are the outcomes of core decompression without augmentation in patients with nontraumatic osteonecrosis of the femoral head?
}

\author{
Octavian Andronic $^{1,2} \cdot$ Ori Weiss $^{2,3} \cdot$ Haitham Shoman ${ }^{2,4} \cdot$ Philipp Kriechling $^{1} \cdot$ Vikas Khanduja $^{2}$ (D)
}

Received: 25 August 2020 / Accepted: 26 August 2020 / Published online: 4 September 2020

(C) The Author(s) 2020

\begin{abstract}
Purpose Core decompression (CD) of the femoral head is performed to preserve the hip in avascular necrosis (AVN). The outcome following this procedure differs based on the medical centre and the technique. Also, the time to total hip replacement (THR) and the percentage of patients subsequently undergoing a THR are controversial.

Methods A systematic review was performed following PRISMA guidelines. The search included CENTRAL, MEDLINE, EMBASE, Scopus, AMED and Web of Science Core Collection databases. Studies reporting the outcome of CD for AVN were assessed. Studies using additional implants, vascularized grafts or any type of augmentation were excluded. Quality assessment was performed using the Joanna Briggs Institute Critical Appraisal Checklist (JBI CAC) tool.

Trial registration International prospective register of systematic reviews (PROSPERO) - CRD42018100596.

Results A total of 49 studies describing 2540 hips were included. The mean weighted follow-up time was 75.1 months and the mean age at surgery was 39 years. Twenty-four of 37 studies reported improvement in all outcome scores, whilst 9/37 studies report only partial improvement post-operatively. Four studies (4/37) described poor clinical outcomes following intervention. Data was pooled from 20 studies, including 1134 hips with a weighted mean follow-up of 56 months. The percentage of hips undergoing THR averaged $38 \%$. The time to THR had a weighted mean of 26 months after CD.

Conclusion Pooled results from 1134 hips and of these nearly $80 \%$ with early stage of osteonecrosis, showed that approximately $38 \%$ of patients underwent a total hip replacement at an average of 26 months following core decompression without augmentation.
\end{abstract}

Keywords Core decompression · Hip preservation · Hip arthroscopy · Avascular osteonecrosis of the femoral head · AVN · Osteonecrosis

Electronic supplementary material The online version of this article (https://doi.org/10.1007/s00264-020-04790-9) contains supplementary material, which is available to authorized users.

Vikas Khanduja

vk279@cam.ac.uk

1 Department of Orthopaedics, Balgrist University Hospital, Forchstrasse 340, 8008 Zürich, Switzerland

2 Young Adult Hip Service, Department of Trauma and Orthopaedics, Addenbrooke's - Cambridge University Hospitals NHS Foundation Trust, Hills Road, Cambridge CB2 0QQ, UK

3 Department of Orthopaedic Surgery, Meir Medical Center, Kfar-Saba, Israel

4 Department of Global Health and Social Medicine, Harvard Medical School, Boston, MA, USA

\section{Introduction}

Osteonecrosis or avascular necrosis (AVN) of the femoral head is a challenging condition that ultimately leads to patients undergoing a total hip replacement (THR) [1]. These patients are young and therefore usually require further revision hip replacements and multiple surgical procedures [2]. The aetiology for AVN is varied and includes a variety of conditions that lead to a compromised blood supply of the femoral head. These include oral corticosteroids, excessive alcohol consumption, Gaucher disease, sickle cell anemia, trauma, thrombosis and systemic lupus erythematosus and in a large proportion of patients, a cause cannot be established and is therefore termed idiopathic [3]. Furthermore, the staging systems for progression of disease are different across the literature and pose a significant challenge in stratifying disease, defining surgical indications and establishing outcomes [4]. The most common 
classification systems in use are Ficat [5] /Modified Ficat [6], University of Pennsylvania/Steinberg [4] and ARCO (Association Research Circulation Osseous) [7-9].

Core decompression is a surgical intervention that is used early in the disease process. The procedure potentially decreases the intraosseous pressure in the femoral head, relieves pain and reestablishes blood flow helping healing of the necrotic fragment. Multiple augmentation techniques with core decompression have also been described and seem to further improve outcomes [10, 11].

However, the eventual outcome and time to THR remains controversial [12-14]. It is also not clear whether a mechanical decompression in the form of core decompression alone is sufficient and efficient enough in all stages of AVN to prevent progression and delay the need for a THR.

The purpose of this study, therefore, was to assess the outcomes and time to THR following core decompression of the femoral head without any augmentation for non-traumatic AVN.

\section{Materials and methods}

\section{Search strategy and criteria}

Two reviewers (OA and OW) searched the online databases (CENTRAL (Cochrane Central Register of Controlled Trials), MEDLINE, EMBASE, Scopus, AMED and Web of Science Core Collection) for literature describing the outcomes of core decompression without augmentation for non-traumatic AVN of the femoral head. A total of eight combinations of the following keywords were used: "femoral head" with "osteonecrosis", "avascular necrosis", "aseptic necrosis", "avn" with the terms - "core decompression" or "surgery". The Preferred Reporting Items for Systematic Reviews and Meta-Analyses (PRISMA) guidelines were used for designing this study. All published studies from inception until January 1,2020 , were included in the systematic search. The protocol of this systematic review has been registered in the international prospective register of systematic reviews (PROSPERO) under the registration number CRD42018100596 and been published recently [15].

\section{Study screening/data abstraction}

A detailed search strategy and the inclusion and exclusion criteria are shown in Table 1. Both the reviewers independently abstracted the relevant study data from the final pool of included articles and recorded this data on a spreadsheet designed a priori. Participant-specific demographics extracted from each study included number of hips, age, gender, body mass index (BMI), presumed primary aetiology, stage of disease, surgical technique, clinical outcome (with preoperative and postoperative results where applicable), radiological outcome, time to joint replacement (THR), average follow-up and specific comments (if any).

\section{Data extraction and quality assessment}

The quality of the RCTs was evaluated as per the guidance of the Cochrane Risk of Bias assessment tool. The quality of all the studies was then assessed using the Joanna Briggs Institute Critical Appraisal Checklist (JBI CAC) [16]. A scoring system was then used per study such as studies that answered yes to a question from the checklist scored 2, not clear scored 1 and no scored 0 . Each score was then converted into a percentage to harmonize the scoring system.

\section{Data analysis and synthesis}

Statistical analyses were performed using SPSS (IBM SPSS Statistics, Version 24.0; Chicago, Illinois) and Graphpad Prism (Graphpad Software, Version 8; San Diego, California).

In order to explore heterogeneity and evaluate studies based on possible confounders, forest plots were developed for calculation of effect size and confidence intervals (95\%). For proportions of hips undergoing hip replacement, the datasets were developed from calculated individual proportions of studies and their confidence intervals. A random effect model was used. Heterogeneity was calculated using Comprehensive Meta-Analysis v2 (CMA), NJ, 07631, USA. According to all of included studies, the $\alpha$ level was set at 0.05 , and all $p$ values were two-tailed.

\section{Interpretation of the forest plots}

Forest plots were presented to summarize the data (Fig. 2). Each horizontal line on a forest plot represents a case series included in the analysis. The length of the line corresponds to a 95\% CI of the corresponding case series' effect estimate. The effect estimate is marked with a solid square. The size of the square represents the weight that the corresponding study exerts in the analysis. The $I^{2}$ value represents the calculated heterogeneity. Values less than $50 \%$ represent mild to moderate heterogeneity, whereas values greater than $50 \%$ represent substantial to considerable heterogeneity.

\section{Results}

\section{Search results and demographics}

The initial search yielded a total of 16411 studies. After removing duplicates, there were 8362 articles. These were then screened for eligibility against the inclusion and exclusion criteria (Table 1) and finally, 49 articles [24-70] were 
Table 1 Study selection criteria

\begin{tabular}{|c|c|}
\hline Inclusion criteria & Exclusion criteria \\
\hline -Human studies in English language from inception until January 1, 2020 & $\cdot$ Non-English articles \\
\hline $\begin{array}{l}\text {-Minimum level IV case series studies using Oxford Centre for Evidence-Based Medicine } \\
2011 \text { Levels of Evidence }\end{array}$ & $\begin{array}{l}\text {-Review/hypothesis/technique articles/oral presentations } \\
\text { or cadaveric/animal studies }\end{array}$ \\
\hline $\begin{array}{l}\text {-Established diagnosis of avascular necrosis of the femoral head, outcomes together with } \\
\text { decompression technique were reported }\end{array}$ & $\begin{array}{l}\text {-Studies including patients who underwent previous } \\
\text { surgery }\end{array}$ \\
\hline -At least 10 hips were evaluated & -Patient population with sickle cell disease \\
\hline $\begin{array}{l}\text {-Patients were classified either based on aetiology or on the stage of the disease: } \\
\text { Ficat/Modified Ficat or University of Pennsylvania/Steinberg or ARCO }\end{array}$ & $\begin{array}{l}\text {-Any type of augmentation was used (e.g. vascularized } \\
\text { bone grafts or bone marrow stem cells) } \\
\text {-Studies including patients with associated trauma or } \\
\text { labral tears }\end{array}$ \\
\hline
\end{tabular}

ARCO Association Research Circulation Osseous

included for the full-text review and definitive analysis (Fig. 1). The reasons for exclusion were noted and are described separately in Suppl. Table 1.

A total of 2540 hips were included in the study. There were 1122 males $(61.5 \%)$ and 702 females (38.5\%). The mean weighted follow-up time was 75.1 months and the mean age at surgery of patients was 39 years. The main aetiologies of AVN included the following: usage of corticosteroids (53.5\% of patients), idiopathic (23.1\% of patients) and alcohol abuse (22.5\% of patients) (Suppl. Table 2). The techniques used for
Fig. 1 Flowchart of the systematic search

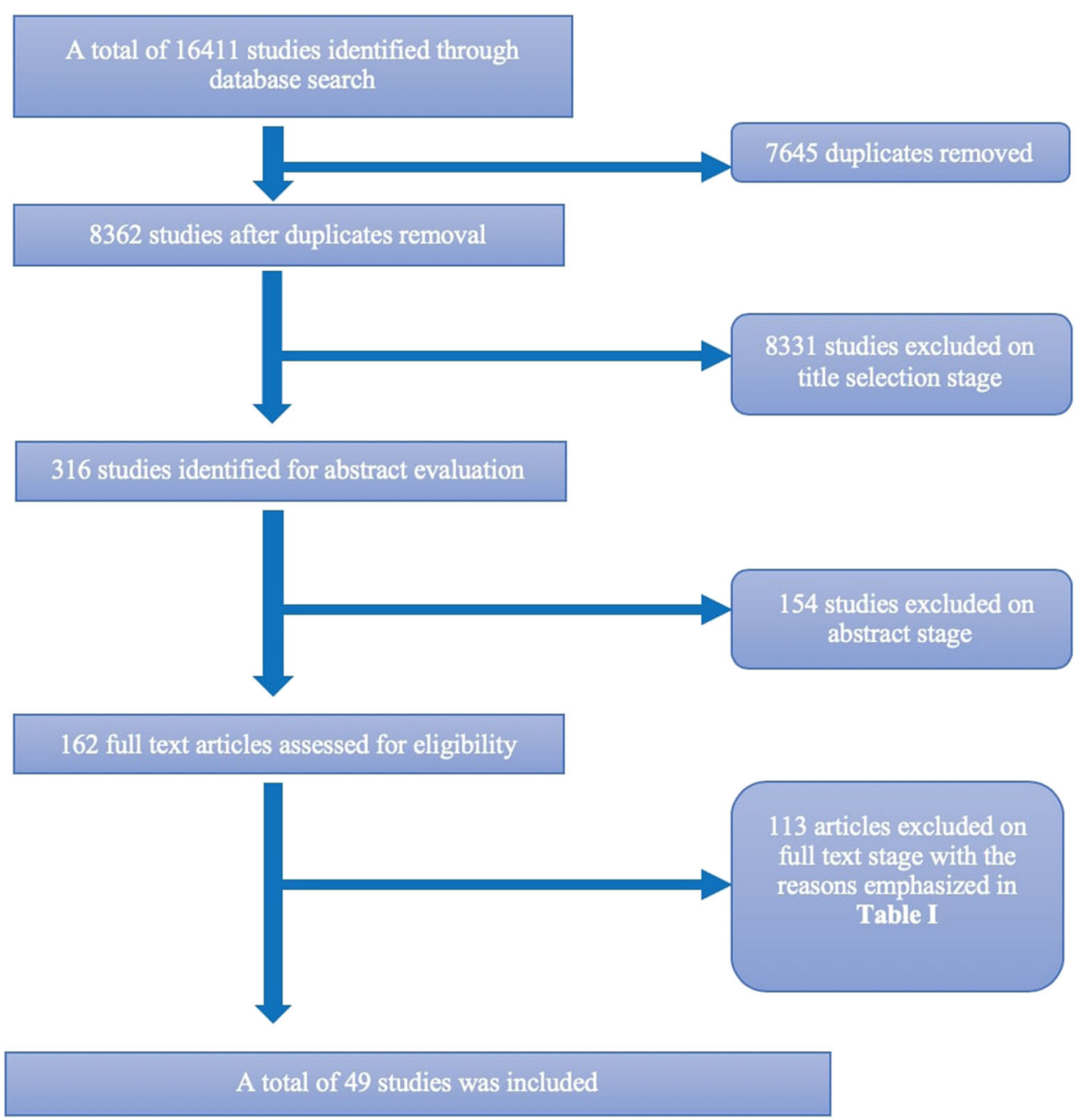


drilling during core decompression were varied. These included simple or multiple drilling using different instruments of different diameters (trephine, cannulated drills, K-wires and Steinman pins with diverse diameters).

\section{Classification systems}

An accentuated heterogeneity was found among the classification systems for staging of the disease. Majority of the studies, $20(40 \%)$, used the original "Ficat" classification [24, 27, $29,32,34,36,41,46,48-52,56-59,61,62,67]$. Ten studies (20\%) followed the "Modified Ficat" classification [12, 25, $31,44,47,54,55,63,65,70]$ and other eleven (22\%) [26, $28,30,37-39,45,60,66,68,69]$ used the ARCO system. Finally, nine studies (18\%) [12, 13, 33, 35, 40, 42, 43, 53, 64] applied the "Steinberg/University of Pennsylvania" classification. There was a single study that reported the hips separately using two classification systems (Modified Ficat/Steinberg) [12].

\section{Quality assessment}

Quality assessment of the 49 studies revealed that there were 27 level IV studies (case series), 12 level III studies, seven level II studies and three level I studies (RCTs — randomized controlled trials). The Joanna Briggs Institute Critical Appraisal Toolkit (JBI-CAT) included the assessment of methodology and of the reported risk of bias (Suppl. Table 2). The studies averaged a score of $82 \%$, which is an indicator of good quality with the majority of studies scoring $75 \%$ or more (37/49).

\section{Clinical and radiological outcome}

Thirty-seven out of 49 studies (76\%) reported data on clinical outcome. Various tools were used for assessment of outcomes in these studies: Merle d'Aubigné-Postel, VAS (visual analogue score), Harris hip score (HHS), WOMAC, SF36Physical, SF36-Mental, Lequesne Index and pain rating index (PRI). There was an obvious lack of a unified reporting tools which required further simplification to interpret the results. As such, the outcomes were simplified down to a binary level: clinical improvement yes or no and radiological progression: yes or no. Post-operative clinical improvement was considered when there was any post-operative improvement reported in the outcome scores. From these, 24/37 studies reported improvement in all outcome scores, whilst $9 / 37$ had only partially achieved better scores post-operatively. Four studies (4/37) described poor outcomes post-operatively. Time to clinical deterioration was reported in $51 \%$ (25/49) of the studies, usually corresponding to the time to a THR.

Due to the lack of separate stratification of pre-operative and post-operative radiological stages in the selected studies, a meaningful statistical summary could not be outlined. Therefore, only a descriptive analysis of the individual studies was performed (Suppl. Table 3-6). The post-operative staging usually mixed the entire cohort of patients, making it impossible to determine which hips did not progress to a THR and which did. However, there were some studies that reported the amount or percentage of hips that did not deteriorate radiologically and these have been recorded in Suppl. Table (3-6).

\section{Total hip replacement}

Both percentage and time to THR following core decompression were documented in 20/49 studies and included a total of 1134 hips (Suppl. Table 7). The pre-operative staging included 890/1134 (78.5\%) of hips with early stages of avascular necrosis and no signs of collapse: Ficat classification (6 studies): stage I and II-180/196, stage III and IV—16/196; modified Ficat classification (4 studies): stage I and II-217/300, stage III and IV-83/300; Steinberg classification (3 studies): stage I + II + III-299/402, stage IV + V + VI-103/402; ARCO classification (7 studies): stage I and II-194/236, stage III and IV— 42/236.

At the final follow-up with a weighted average of 56 months, 431/1134 (38\%) hips were converted to a THR at a calculated weighted average time of 26.3 months (Suppl. Table 7).

The pooled proportion of hips undergoing total hip replacement was $38 \%$ (95\% confidence interval with lower limit of $35.3 \%$ to upper limit of $41.1 \%$ ) from 20 studies with a total of 1134 cases. There was statistical significance regarding heterogeneity $\left(I^{2}\right.$ value $\left.>80 \%, p<0.0001\right)$ showing the inconsistency of methodological aspects between the studies included in the analysis, which did not allow a detailed metaanalysis (Fig. 2). For further stratification, studies were separately evaluated based on the most probable confounders: inclusion of post-collapse stages in the study population (Suppl. Fig. 1), design (prospective/retrospective) (Suppl. Fig. 2) and average time to total hip replacement (early $<24$ months and late $>24$ months) (Fig. 3). This could not, however, significantly reduce the heterogeneity, as all $I^{2}$ values were above $60 \%$, which may represent substantial heterogeneity regardless of the abovementioned stratification efforts.

\section{Discussion}

Osteonecrosis of the femoral head is a devastating condition for the young adult. Depending on severity of the disease, these patients may require a THR at a particularly young age and are, therefore, likely to require a revision and perhaps a re-revision of their prosthesis at some point in their lives [17]. Early diagnosis, prompt intervention and refining of joint-preserving procedures are therefore especially important in order to avoid or at least delay the need for joint replacement in this unique cohort. 
Fig. 2 Proportion forest plot of studies reporting percentage of hips undergoing total hip replacement after core decompression. Eventconversion to THA (total hip arthroplasty). The size of the square represents the weight that the corresponding study exerts. $I^{2}$ - value of calculated heterogeneity

\begin{tabular}{|c|c|c|c|c|c|}
\hline \multirow[t]{2}{*}{ Study name } & \multicolumn{5}{|c|}{ Statistics for each study } \\
\hline & $\begin{array}{r}\text { Event } \\
\text { rate }\end{array}$ & $\begin{array}{c}\text { Lower } \\
\text { limit }\end{array}$ & $\begin{array}{r}\text { Upper } \\
\text { limit }\end{array}$ & Z-Value & p-Valc \\
\hline r 2002 & 0.156 & 0.076 & 0.292 & -4.113 & 0.00 \\
\hline 988 & 0.429 & 0.240 & 0.640 & -0.652 & 0.514 \\
\hline 9 & 0.278 & 0.156 & 0.444 & -2.568 & 0.010 \\
\hline en 2015 & 0.333 & 0.234 & 0.449 & -2.773 & 0.006 \\
\hline $\operatorname{ardos} 2$ & 0.421 & 0.226 & 0.644 & -0.685 & 0.493 \\
\hline & 0.273 & 0.090 & 0.586 & -1.449 & 0.147 \\
\hline eur 2017 & 0.652 & 0.443 & 0.816 & 1.436 & 0.151 \\
\hline te 2005 & 0.377 & 0.322 & 0.435 & -4.050 & 0.000 \\
\hline 2011 & 0.288 & 0.182 & 0.425 & -2.950 & 0.003 \\
\hline g 2018 & 0.491 & 0.360 & 0.623 & -0.137 & 0.891 \\
\hline en 1990 & 0.517 & 0.341 & 0.689 & 0.186 & 0.853 \\
\hline honth 1990 & 0.439 & 0.297 & 0.592 & -0.779 & 0.436 \\
\hline 1996 & 0.481 & 0.353 & 0.613 & -0.272 & 0.786 \\
\hline 2017 & 0.634 & 0.479 & 0.766 & 1.696 & 0.090 \\
\hline n 2017 & 0.382 & 0.237 & 0.553 & -1.359 & 0.174 \\
\hline 2007 & 0.307 & 0.241 & 0.382 & -4.800 & 0.000 \\
\hline ke 1988 & 0.444 & 0.308 & 0.590 & -0.744 & 0.457 \\
\hline 2015 & 0.095 & 0.036 & 0.228 & -4.283 & 0.000 \\
\hline 2016 & 0.269 & 0.134 & 0.467 & -2.258 & 0.024 \\
\hline 2000 & 0.487 & 0.336 & 0.640 & -0.160 & 0.87 \\
\hline & 0.382 & 0.354 & 0.412 & -7.539 & 0.00 \\
\hline
\end{tabular}

I square $=67 \%$

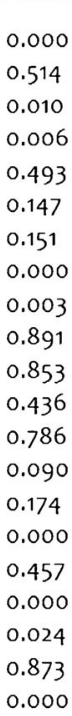

$\mid$
Event rate and $95 \% \mathrm{Cl}$

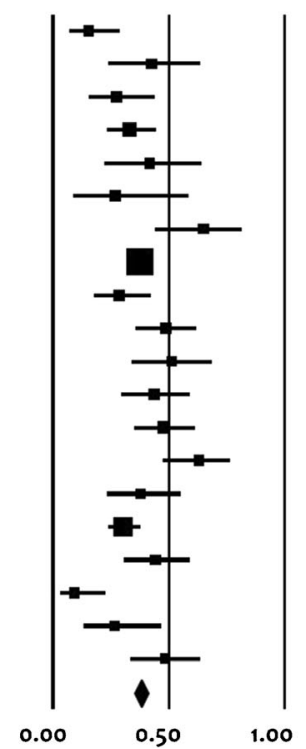

Deciding the best treatment algorithm for a young and active patient presenting with avascular necrosis can be challenging. It should commence with selecting a good classification system from the many available that would offer accuracy in evaluating

\begin{tabular}{|c|c|}
\hline Study name & Avg Time to T \\
\hline Aigner 2002 & $>2$ years \\
\hline Bi 2019 & $>2$ years \\
\hline Cruzpardos 2016 & $>2$ years \\
\hline Gangji 2011 & $>2$ years \\
\hline Israelite 2005 & $>2$ years \\
\hline Kang 2011 & $>2$ years \\
\hline Kang 2018 & $>2$ years \\
\hline Sallam 2017 & $>2$ years \\
\hline Song 2007 & $>2$ years \\
\hline Arlet 1988 & $<2$ years \\
\hline Classen 2015 & $<2$ years \\
\hline Hauzeur 2017 & $<2$ years \\
\hline Lausten 1990 & $<2$ years \\
\hline Learmonth 1990 & $<2$ years \\
\hline Markel 1996 & $<2$ years \\
\hline Sadile 2017 & $<2$ years \\
\hline Tooke 1988 & $<2$ years \\
\hline Yan 2015 & $<2$ years \\
\hline Yin 2016 & $<2$ years \\
\hline Yoon 2000 & $<2$ years \\
\hline
\end{tabular}

Statistics for each study

Event rate and $95 \% \mathrm{Cl}$

Event Lower Upper

rate limit limit z-Value p-Value

$\begin{array}{lllll}0.156 & 0.076 & 0.292 & -4.113 & 0.000 \\ 0.278 & 0.156 & 0.444 & -2.568 & 0.010 \\ 0.421 & 0.226 & 0.644 & -0.685 & 0.493 \\ 0.273 & 0.090 & 0.586 & -1.449 & 0.147 \\ 0.377 & 0.322 & 0.435 & -4.050 & 0.000 \\ 0.288 & 0.182 & 0.425 & -2.950 & 0.003 \\ 0.491 & 0.360 & 0.623 & -0.137 & 0.891 \\ 0.382 & 0.237 & 0.553 & -1.359 & 0.174 \\ 0.307 & 0.241 & 0.382 & -4.800 & 0.000 \\ 0.347 & 0.312 & 0.384 & -7.752 & 0.000\end{array}$

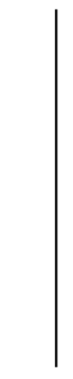

$-1.00$

I square $=69 \%$

$\begin{array}{lllll}0.429 & 0.240 & 0.640 & -0.652 & 0.514 \\ 0.333 & 0.234 & 0.449 & -2.773 & 0.006 \\ 0.652 & 0.443 & 0.816 & 1.436 & 0.151 \\ 0.517 & 0.341 & 0.689 & 0.186 & 0.853 \\ 0.439 & 0.297 & 0.592 & -0.779 & 0.436 \\ 0.481 & 0.353 & 0.613 & -0.272 & 0.786 \\ 0.634 & 0.479 & 0.766 & 1.696 & 0.090 \\ 0.444 & 0.308 & 0.590 & -0.744 & 0.457 \\ 0.095 & 0.036 & 0.228 & -4.283 & 0.000 \\ 0.269 & 0.134 & 0.467 & -2.258 & 0.024 \\ 0.487 & 0.336 & 0.640 & -0.160 & 0.873 \\ 0.440 & 0.391 & 0.490 & -2.371 & 0.018\end{array}$

I square $=50 \%$
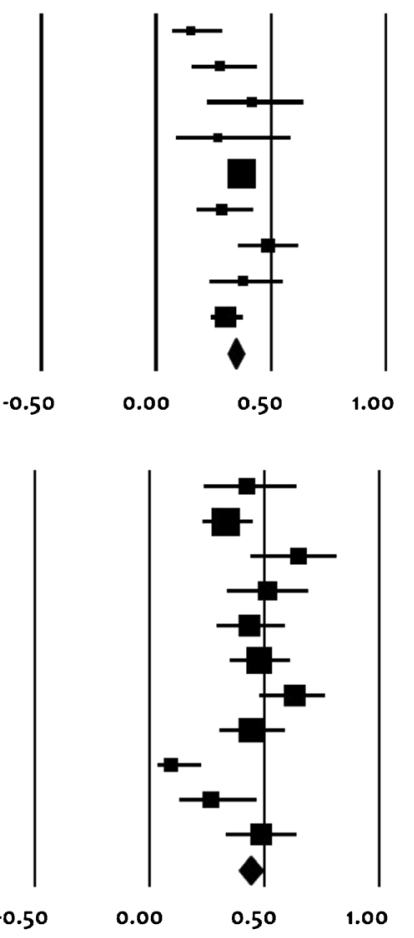

Fig. 3 Forest plot differentiating studies with early conversion to total hip arthroplasty (average time to THA $<24$ months) versus late conversions (average time to THA > 24 months). Event—conversion to THA (total hip arthroplasty). The size of the square represents the weight that the corresponding study exerts. $I^{2}$-value of calculated heterogeneity 
disease progression and stratifying the disease. The optimal treatment of the pre-collapse stage of (ARCO stage 1 and 2) avascular necrosis is controversial. Core decompression is the most commonly performed procedure for treating pre-collapse osteonecrosis, as it has also been shown to be the only costeffective technique $[18,19]$. Increased intramedullary pressure is considered to be at the root cause of the pathophysiology, as it is thought to potentially block off the perfusion to the head of the femur. CD works by drilling one or multiple tunnels from the greater trochanter, through the femoral neck, and into the subchondral bone of the femoral head thereby reducing the intramedullary pressure, promoting blood supply and allowing the necrotic segment to heal [20].

Our study shows that core decompression provides only short-term clinical improvement and partial or complete pain relief in most of the cases (33 out of 37 studies reported postoperative clinical improvement). It should however be noted that reduction of pain may be due to temporary reduction of weight-bearing during the rehabilitation phase and further trials evaluating this aspect are necessary. Our results also demonstrates that approximately $38 \%$ of patients underwent a total hip replacement at an average of 26 months following core decompression without augmentation in a large and diverse population with AVN of the femoral head of varied aetiology. This review, however, could not determine whether core decompression alone can arrest disease progression due to lack of stratification and heterogeneity of data.

Our study reveals that the risk of conversion to a THR is fairly high in the shorter term with core decompression alone. It remains to be seen whether augmentation procedures can better these results and obviate the need for a THR in this cohort of patients.

Previous studies looking at the outcomes following core decompression either have gaps in the inclusion and exclusion criteria, are limited by the number of cases included or have mixed all augmentation techniques with core decompression which makes it difficult to interpret the outcomes of core decompression alone as a surgical intervention [21-23]. Our study represents an effort to summarize all the available evidence, which describes core decompression of the femoral head as a sole procedure without additional augmentation, e.g. bone marrow grafting.

There are limitations of our study and most of them are directly linked to the individual limitations of the included studies and heterogeneity of data. The reporting systems were highly variable, from different clinical scores HHS/D'Aubigne/ VAS to differing classifications used for staging disease (Ficat or its modification, Steinberg, ARCO). Furthermore, the concept of "procedural success" was not absolute. Whilst most studies considered the absence of radiological progression to be the main finding that suggested success, other authors interpreted clinical improvement as being a success, even in the presence of radiographic deterioration. Not reporting the outcome separately for every single stage subgroup was the biggest challenge in assessment of radiological outcome. Most studies reported the distribution of pre-operative and post-operative radiological stages, without specifically describing which hips actually deteriorated, making it tedious to track longitudinal change for each hip. As such, no conclusions could be made regarding the implications of the preoperative area of osteonecrosis. Also, the lack of granularity and the presence of significant heterogeneity in the data analysed did not allow stratification of outcome based on each specific aetiology (idiopathic/corticosteroids/alcohol abuse or other), as the postoperative outcome was reported cumulative for all patients. This is applied not only to clinical data or radiographic staging but also to conversion rates to THA, which could not be extracted for each aetiology separately.

However, despite these limitations, the strengths of our study are represented by the large patient pool and by the rigorous exclusion criteria that was used. The collateral influence of aetiology (traumatic), systemic disease (sickle cell crisis) or technique heterogeneity (presence of augmentation or bone grafts) was excluded. Also, there was a tenacious stratification based on stage of the disease even in the presence of a variety of classification systems which makes this study unique.

A significant amount of work has been done recently by the ARCO group [7-9] to define the aetiology and arrive at a consensus statement to revise the ARCO classification. Going forward, this classification should be used universally, along with a specific criterion for defining "procedural success" to allow future studies to compare results and avoid heterogeneity in data.

Despite a high degree of heterogeneity amongst studies, core decompression alone achieved short-term clinical improvement in majority of the cases. Pooled results from 1134 hips and of these nearly $80 \%$ with early stage of osteonecrosis, showed that approximately $38 \%$ of patients underwent a total hip replacement at an average of 26 months following core decompression without augmentation. Future studies should report outcome by stratifying it based on preoperative stages as proposed by the ARCO group and postcollapse stages of osteonecrosis should be excluded.

Authorship All authors have made substantial contributions: Octavian Andronic. OA: conceptualization, formal analysis, investigation, methodology, project administration, resources, software, supervision, writingoriginal draft preparation, writing - review and editing. HS: investigation, methodology, validation, writing - review and editing. KP: investigation, systematic search, quality assessment, expert statistical appraisal, manuscript writing and editing. OW: formal analysis, investigation, resources, visualization, writing — original draft preparation. VK: conceptualization, investigation, methodology, project administration, supervision, validation, writing - review and editing.

\section{Compliance with ethical standards}

Informed consent Not applicable. 
Ethical approval Was not required

Competing interests All authors have completed the ICMJE uniform disclosure form at www.icmje.org/coi_disclosure.pdf and declare that they have no conflict of interest.

Open Access This article is licensed under a Creative Commons Attribution 4.0 International License, which permits use, sharing, adaptation, distribution and reproduction in any medium or format, as long as you give appropriate credit to the original author(s) and the source, provide a link to the Creative Commons licence, and indicate if changes were made. The images or other third party material in this article are included in the article's Creative Commons licence, unless indicated otherwise in a credit line to the material. If material is not included in the article's Creative Commons licence and your intended use is not permitted by statutory regulation or exceeds the permitted use, you will need to obtain permission directly from the copyright holder. To view a copy of this licence, visit http://creativecommons.org/licenses/by/4.0/.

\section{References}

1. Steinberg ME, Larcom PG, Strafford B, Hosick WB, Corces A, Bands RE, Hartman KE (2001) Core decompression with bone grafting for osteonecrosis of the femoral head. A Publication of The Association of Bone and Joint Surgeons ${ }^{\circledR} \mid$ CORR® 386:71-78

2. Bergh C, Fenstad AM, Furnes O, Garellick G, Havelin LI, Overgaard S, Pedersen AB, Makela KT, Pulkkinen P, Mohaddes M, Karrholm J (2014) Increased risk of revision in patients with non-traumatic femoral head necrosis. Acta Orthop 85(1):11-17. https://doi.org/10.3109/17453674.2013.874927

3. Shah KN, Racine J, Jones LC, Aaron RK (2015) Pathophysiology and risk factors for osteonecrosis. Curr Rev Musculoskelet Med 8(3):201-209. https://doi.org/10.1007/s12178-015-9277-8

4. Sultan AA, Mohamed N, Samuel LT, Chughtai M, Sodhi N, Krebs VE, Stearns KL, Molloy RM, Mont MA (2018) Classification systems of hip osteonecrosis: an updated review. Int Orthop. https:// doi.org/10.1007/s00264-018-4018-4

5. Jawad MU, Haleem AA, Scully SP (2012) In brief: Ficat classification: avascular necrosis of the femoral head. Clin Orthop Relat Res 470(9):2636-2639. https://doi.org/10.1007/s11999-012-24162

6. Smith SW, Meyer RA, Connor PM, Smith SE, Hanley EN Jr (1996) Interobserver reliability and intraobserver reproducibility of the modified Ficat classification system of osteonecrosis of the femoral head. J Bone Joint Surg Am 78(11):1702-1706

7. Yoon BH, Jones LC, Chen CH, Cheng EY, Cui Q, Drescher W, Fukushima W, Gangji V, Goodman SB, Ha YC, Hernigou P, Hungerford M, Iorio R, Jo WL, Khanduja V, Kim H, Kim SY, Kim TY, Lee HY, Lee MS, Lee YK, Lee YJ, Mont MA, Sakai T, Sugano N, Takao M, Yamamoto T, Koo KH (2019) Etiologic classification criteria of ARCO on femoral head osteonecrosis Part 2: alcohol-associated osteonecrosis. J Arthroplast 34(1):169174.e161. https://doi.org/10.1016/j.arth.2018.09.006

8. Yoon BH, Jones LC, Chen CH, Cheng EY, Cui Q, Drescher W, Fukushima W, Gangji V, Goodman SB, Ha YC, Hernigou P, Hungerford M, Iorio R, Jo WL, Khanduja V, Kim H, Kim SY, Kim TY, Lee HY, Lee MS, Lee YK, Lee YJ, Mont MA, Sakai T, Sugano N, Takao M, Yamamoto T, Koo KH (2019) Etiologic classification criteria of ARCO on femoral head osteonecrosis Part 1: glucocorticoid-associated osteonecrosis. J Arthroplast 34(1):163168.e161. https://doi.org/10.1016/j.arth.2018.09.005
9. Yoon BH, Mont MA, Koo KH, Chen CH, Cheng EY, Cui Q, Drescher W, Gangji V, Goodman SB, Ha YC, Hernigou P, Hungerford MW, Iorio R, Jo WL, Jones LC, Khanduja V, Kim HKW, Kim SY, Kim TY, Lee HY, Lee MS, Lee YK, Lee YJ, Nakamura J, Parvizi J, Sakai T, Sugano N, Takao M, Yamamoto T, Zhao DW (2020) The 2019 revised version of association research circulation osseous staging system of osteonecrosis of the femoral head. J Arthroplast 35(4):933-940. https://doi.org/10. 1016/j.arth.2019.11.029

10. Arbeloa-Gutierrez L, Dean CS, Chahla J, Pascual-Garrido C (2016) Core decompression augmented with autologous bone marrow aspiration concentrate for early avascular necrosis of the femoral head. Arthrosc Tech 5(3):e615-e620. https://doi.org/10.1016/j. eats.2016.02.009

11. Ma Y, Wang T, Liao J, Gu H, Lin X, Jiang Q, Bulsara MK, Zheng M, Zheng Q (2014) Efficacy of autologous bone marrow buffy coat grafting combined with core decompression in patients with avascular necrosis of femoral head: a prospective, double-blinded, randomized, controlled study. Stem Cell Res Ther 5(5):115. https:// doi.org/10.1186/scrt505

12. Markel DC, Miskovsky C, Sculco TP, Pellicci PM, Salvati EA (1996) Core decompression for osteonecrosis of the femoral head. Clin Orthop Relat Res 323:226-233

13. Simank HG, Brocai DR, Brill C, Lukoschek M (2001) Comparison of results of core decompression and intertrochanteric osteotomy for nontraumatic osteonecrosis of the femoral head using Cox regression and survivorship analysis. J Arthroplast 16(6):790-794. https://doi.org/10.1054/arth.2001.23580

14. Yoon BH, Lee YK, Kim KC, Ha YC, Koo KH (2018) No differences in the efficacy among various core decompression modalities and non-operative treatment: a network meta-analysis. Int Orthop. https://doi.org/10.1007/s00264-018-3977-9

15. Andronic O, Shoman H, Weiss O, Khanduja V (2020) What are the outcomes of core decompression in patients with avascular necrosis? Protocol for a systematic review [version 1; peer review: 2 approved]. F1000Research 9(71). https://doi.org/10.12688/ f1000research.22167.1

16. Aromataris E, Fernandez R, Godfrey CM, Holly C, Khalil H, Tungpunkom P (2015) Summarizing systematic reviews: methodological development, conduct and reporting of an umbrella review approach. Int J Evid Based Healthc 13(3):132-140. https://doi.org/ 10.1097/xeb.0000000000000055

17. Ancelin D, Reina N, Cavaignac E, Delclaux S, Chiron P (2016) Total hip arthroplasty survival in femoral head avascular necrosis versus primary hip osteoarthritis: case-control study with a mean 10-year follow-up after anatomical cementless metal-on-metal 28mm replacement. Orthop Traumatol Surg Res 102(8):1029-1034. https://doi.org/10.1016/j.otsr.2016.08.021

18. Tripathy S, Goyal T, Sen R (2015) Management of femoral head osteonecrosis: current concepts. Indian J Orthop 49(1):28-45. https://doi.org/10.4103/0019-5413.143911

19. Soohoo NF, Vyas S, Manunga J, Sharifi H, Kominski G, Lieberman JR (2006) Cost-effectiveness analysis of core decompression. J Arthroplast 21(5):670-681. https://doi.org/10.1016/j. arth.2005.08.018

20. Marker DR, Seyler TM, Ulrich SD, Srivastava S, Mont MA (2008) Do modern techniques improve core decompression outcomes for hip osteonecrosis? Clin Orthop Relat Res 466(5):1093-1103. https://doi.org/10.1007/s11999-008-0184-9

21. Wang Z, Sun QM, Zhang FQ, Zhang QL, Wang LG, Wang WJ (2019) Core decompression combined with autologous bone marrow stem cells versus core decompression alone for patients with osteonecrosis of the femoral head: a meta-analysis. Int J Surg (London, England) 69:23-31. https://doi.org/10.1016/j.ijsu.2019. 06.016 
22. Zhang C, Fang X, Huang Z, Li W, Zhang W, Lee GC (2020) Addition of bone marrow stem cells therapy achieves better clinical outcomes and lower rates of disease progression compared with core decompression alone for early stage osteonecrosis of the femoral head: a systematic review and meta-analysis. J Am Acad Orthop Surg. https://doi.org/10.5435/jaaos-d-19-00816

23. Xu S, Zhang L, Jin H, Shan L, Zhou L, Xiao L, Tong P (2017) Autologous stem cells combined core decompression for treatment of avascular necrosis of the femoral head: a systematic meta-analysis. Biomed Res Int 2017:6136205. https://doi.org/10.1155/2017/ 6136205

24. Aaron RK, Lennox D, Bunce GE, Ebert T (1989) The conservative treatment of osteonecrosis of the femoral head. A comparison of core decompression and pulsing electromagnetic fields. Clin Orthop Relat Res (249):209-218

25. Abrisham SMJ, Hajiesmaeili MR, Soleimani H, Pahlavanhosseini H (2013) Efficacy of core decompression of femoral head to treat avascular necrosis in intravenous drug users. Acta Med Iran 51(4): 250-253

26. Aigner N, Schneider W, Eberl V, Knahr K (2002) Core decompression in early stages of femoral head osteonecrosis-an MRIcontrolled study. Int Orthop 26(1):31-35

27. Arlet J, Ficat C (1990) Ischemic necrosis of the femoral head. Treatment by core decompression. J Bone Joint Surg Am 72(1): $151-152$

28. Beckmann J, Schmidt T, Schaumburger J, Rath B, Lüring C, Tingart M, Grifka J (2013) Infusion, core decompression, or infusion following core decompression in the treatment of bone edema syndrome and early avascular osteonecrosis of the femoral head. Rheumatol Int 33(6):1561-1565. https://doi.org/10.1007/s00296012-2597-8

29. Beltran J, Knight CT, Zuelzer WA, Morgan JP, Shwendeman LJ, Chandnani VP, Mosure JC, Shaffer PB (1990) Core decompression for avascular necrosis of the femoral head: correlation between long-term results and preoperative MR staging. Radiology 175(2): 533-536. https://doi.org/10.1148/radiology.175.2.2326478

30. Bi B, Zhang S, Zhao Y (2019) The effect of robot-navigationassisted core decompression on early stage osteonecrosis of the femoral head. J Orthop Surg Res 14(1):375. https://doi.org/10. 1186/s13018-019-1437-x

31. Bozic KJ, Zurakowski D, Thornhill TS (1999) Survivorship analysis of hips treated with core decompression for nontraumatic osteonecrosis of the femoral head. J Bone Joint Surg Am 81(2): 200-209

32. Chen Q, Qian L, Zhang L, Wang DS, Pan Q, Wu QM, He M, Jin Y, Chen Y, Huang RH, Zhai Y, Luo JY, Liao D, Xiao Y, Sunwen YM (2016) Core decompression combined with superselective arterial infusion in treating early nontraumatic osteonecrosis of femoral head. Int J Clin Exp Med 9(6):10281-10288

33. Classen T, Warwas S, Jäger M, Landgraeber S (2017) Two-year follow-up after advanced core decompression. J Tissue Eng Regen Med 11(4):1308-1314. https://doi.org/10.1002/term.2056

34. Cruz-Pardos A, Garcia-Rey E, Ortega-Chamarro JA, DuranManrique D, Gomez-Barrena E (2016) Mid-term comparative outcomes of autologous bone-marrow concentration to treat osteonecrosis of the femoral head in standard practice. Hip Int 26(5):432-437. https://doi.org/10.5301/hipint.5000366

35. Etemadifar M, Kooskzari M, Khalilollah N, Ali MK, Mahsa B (2014) The results of core decompression treatment in patients with avascular necrosis of femoral head in patients at Isfahan City educational hospitals in 2010-2011. Adv Biomed Res 3:93. https://doi. org/10.4103/2277-9175.129363

36. Fairbank AC, Bhatia D, Jinnah RH, Hungerford DS (1995) Longterm results of core decompression for ischaemic necrosis of the femoral head. J Bone Joint Surg Br Vol 77(1):42-49
37. Gangii V, Maertelaer V, Hauzeur J-P (2011) Autologous bone marrow cell implantation in the treatment of non-traumatic osteonecrosis of the femoral head: five year follow-up of a prospective controlled study. Bone 49(5):1005-1009. https://doi.org/10. 1016/j.bone.2011.07.032

38. Haberal B, Sahin O, Simsek EK, Mahmuti A, Tuncay IC (2018) Outcomes for core decompression with multiple drilling of the osteonecrosis of the femoral head in patients with solid organ transplantation. Eklem Hastaliklari Cerrahisi 29(3):159-164. https://doi. org/10.5606/ehc.2018.61348

39. Hauzeur JP, De Maertelaer V, Baudoux E, Malaise M, Beguin Y, Gangji V (2018) Inefficacy of autologous bone marrow concentrate in stage three osteonecrosis: a randomized controlled double-blind trial. Int Orthop 42(7):1429-1435. https://doi.org/10.1007/s00264017-3650-8

40. Hernigou P, Dubory A, Homma Y, Guissou I, Lachaniette CHF, Chevallier N, Rouard H (2018) Cell therapy versus simultaneous contralateral decompression in symptomatic corticosteroid osteonecrosis: a thirty year follow-up prospective randomized study of one hundred and twenty five adult patients. Int Orthop 42(7): 1639-1649. https://doi.org/10.1007/s00264-018-3941-8

41. Iorio R, Healy WL, Abramowitz AJ, Pfeifer BA (1998) Clinical outcome and survivorship analysis of core decompression for early osteonecrosis of the femoral head. J Arthroplast 13(1):34-41

42. Israelite C, Nelson CL, Ziarani CF, Abboud JA, Landa J, Steinberg ME (2005) Bilateral core decompression for osteonecrosis of the femoral head. Clin Orthop Relat Res 441:285-290

43. Ito H, Matsuno T, Omizu N, Aoki Y, Minami A (2003) Mid-term prognosis of non-traumatic osteonecrosis of the femoral head. $\mathrm{J}$ Bone Joint Surg Br Vol 85(6):796-801

44. Kang P, Pei F, Shen B, Zhou Z, Yang J (2012) Are the results of multiple drilling and alendronate for osteonecrosis of the femoral head better than those of multiple drilling? A pilot study. Joint Bone Spine 79(1):67-72. https://doi.org/10.1016/j.jbspin.2011.02.020

45. Kang JS, Suh YJ, Moon KH, Park JS, Roh TH, Park MH, Ryu DJ (2018) Clinical efficiency of bone marrow mesenchymal stem cell implantation for osteonecrosis of the femoral head: a matched pair control study with simple core decompression. Stem Cell Res Ther 9(1):274. https://doi.org/10.1186/s13287-018-1030-y

46. Kristensen KD, Pedersen NW, Kiaer T, Starklint H (1991) Core decompression in femoral head osteonecrosis. 18 Stage I hips followed up for 1-5 years. Acta Orthop Scand 62(2):113-114

47. Lakshminarayana S, Dhammi I, Jain A, Bhayana H, Kumar S, Anshuman R (2019) Outcomes of core decompression with or without nonvascularized fibular grafting in avascular necrosis of femoral head: short term followup study. Indian J Orthop 53(3): 420-425. https://doi.org/10.4103/ortho.IJOrtho_310_18

48. Lausten GS, Mathiesen B (1990) Core decompression for femoral head necrosis. Prospective study of 28 patients. Acta Orthop Scand 61(6):507-511

49. Learmonth ID, Maloon S, Dall G (1990) Core decompression for early atraumatic osteonecrosis of the femoral head. J Bone Joint Surg Br Vol 72(3):387-390

50. Li J, Li ZL, Zhang H, Su XZ, Wang KT, Yang YM (2017) Longterm outcome of multiple small-diameter drilling decompression combined with hip arthroscopy versus drilling alone for early avascular necrosis of the femoral head. Chin Med J 130(12):1435-1440. https://doi.org/10.4103/0366-6999.207470

51. Maniwa S, Nishikori T, Furukawa S, Kajitani K, Iwata A, Nishikawa U, Ochi M (2000) Evaluation of core decompression for early osteonecrosis of the femoral head. Arch Orthop Trauma Surg 120(5-6):241-244

52. Mazières B, Marin F, Chiron P, Moulinier L, Amigues JM, Laroche M, Cantagrel A (1997) Influence of the volume of osteonecrosis on the outcome of core decompression of the femoral head. Ann Rheum Dis 56(12):747-750. https://doi.org/10.1136/ard.56.12.747 
53. Miao H, Ye D, Liang W, Yao Y (2015) Effect of Osteonecrosis intervention rod versus core decompression using multiple small drill holes on early stages of necrosis of the femoral head: a prospective study on a series of 60 patients with a minimum 1-yearfollow-up. Open Orthop J 9:179-184. https://doi.org/10.2174/ 1874325001509010179

54. Miyahara HS, Rosa BB, Hirata FY, Gurgel HMC, Ejnisman L, Vicente JRN (2018) What is the role of core decompression in the early stages of osteonecrosis of the femoral head? Evaluation of the surgical result by functional score and radiological follow-up. Rev Bras Ortop 53(5):537-542. https://doi.org/10.1016/j.rboe.2018.07. 013

55. Mohanty SP, Singh KA, Kundangar R, Shankar V (2017) Management of non-traumatic avascular necrosis of the femoral head - a comparative analysis of the outcome of multiple small diameter drilling and core decompression with fibular grafting. Musculoskelet Surg 101(1):59-66. https://doi.org/10.1007/ s12306-016-0431-2

56. Mont MA, Fairbank AC, Petri M, Hungerford DS (1997) Core decompression for osteonecrosis of the femoral head in systemic lupus erythematosus. Clin Orthop Relat Res 334:91-97

57. Mont MA, Jones LC, Pacheco I, Hungerford DS (1998) Radiographic predictors of outcome of core decompression for hips with osteonecrosis stage III. Clin Orthop Relat Res 354:159-168

58. Mont MA, Ragland PS, Etienne G (2004) Core decompression of the femoral head for osteonecrosis using percutaneous multiple small-diameter drilling. Clin Orthop Relat Res 429:131-138

59. Nori M, Marupaka SK, Alluri S, Naseeruddin MD, Irfan KA, Jampala V, Apsingi S, Eachempati KK (2015) MRI evaluation of post core decompression changes in avascular necrosis of HiP. $\mathrm{J}$ Clin Diagn Res 9(12):TC04-TC08. https://doi.org/10.7860/JCDR/ 2015/13995.6967

60. Pepke W, Kasten P, Beckmann NA, Janicki P, Egermann M (2016) Core decompression and autologous bone marrow concentrate for treatment of femoral head osteonecrosis: a randomized prospective study. Orthop Rev 8(1):6162. https://doi.org/10.4081/or.2016.6162

61. Powell Iv ET, Lanzer WL, Mankey MG (1997) Core decompression for early osteonecrosis of the hip in high risk patients. Clin Orthop Relat Res 335:181-189

62. Sadile F, Bernasconi A, Carbone F, Lintz F, Mansueto G (2017) Histological fibrosis may predict the failure of core decompression in the treatment of osteonecrosis of the femoral head. Int J Surg (London, England) 44:303-308. https://doi.org/10.1016/j.ijsu. 2017.06.079

63. Sallam AA, Imam MA, Salama KS, Mohamed OA (2017) Inverted femoral head graft versus standard core decompression in nontraumatic hip osteonecrosis at minimum 3 years follow-up. Hip Int 27(1):74-81. https://doi.org/10.5301/hipint.5000426

64. Simank HG, Brocai DR, Strauch K, Lukoschek M (1999) Core decompression in osteonecrosis of the femoral head: risk-factordependent outcome evaluation using survivorship analysis. Int Orthop 23(3):154-159

65. Song WS, Yoo JJ, Kim YM, Kim HJ (2007) Results of multiple drilling compared with those of conventional methods of core decompression. Clin Orthop Relat Res 454:139-146. https://doi.org/ 10.1097/01.blo.0000229342.96103.73

66. Tabatabaee R, Saberi S, Parvizi J, Mortazavi S, Farzan M (2015) Combining concentrated autologous bone marrow stem cells injection with core decompression improves outcome for patients with early-stage osteonecrosis of the femoral head: a comparative study. J Arthroplasty 30(9 Suppl):11-15. https://doi.org/10.1016/j.arth. 2015.06.022

67. Tooke SM, Nugent PJ, Bassett LW, Nottingham P, Mirra J, Jinnah R (1988) Results of core decompression for femoral head osteonecrosis. Clin Orthop Relat Res 228:99-104

68. Yan D, Chen L, Li Z, Guo W, Sun W (2015) Autologous mesenchymal stem cell implantation in the management of osteonecrosis of the femoral head. Curr Orthop Pract 26(3):265-268. https://doi. org/10.1097/BCO.0000000000000218

69. Yin H, Yuan Z, Wang D (2016) Multiple drilling combined with simvastatin versus multiple drilling alone for the treatment of avascular osteonecrosis of the femoral head: 3-year follow-up study. BMC Musculoskelet Disord 17(1):344. https://doi.org/10.1186/ s12891-016-1199-0

70. Yoon TR, Song EK, Rowe SM, Park CH (2001) Failure after core decompression in osteonecrosis of the femoral head. Int Orthop 24(6):316-318

Publisher's note Springer Nature remains neutral with regard to jurisdictional claims in published maps and institutional affiliations. 